\title{
Vivência do professor no cotidiano da criança com estomia: abordagem da
}

\section{Fenomenologia Social}

\author{
Manuela Costa Melo ${ }^{1}$, Ivone Kamada ${ }^{2}$, Luz Marina Alfonso Dutra ${ }^{3}$, \\ João Filipe Fernandes Lindo Simões ${ }^{4}$, Elsa Maria Oliveira Pinheiro de Melo ${ }^{5}$
}

\footnotetext{
* Esse artigo é um recorte da Tese de Doutorado intitulada "Vivência e experiência no cuidado da criança com estomia na perspectiva dos familiares e dos professores" defendida em 2017 no Programa de Pós-Graduação em Enfermagem da Universidade de Brasília, Brasília, DF, Brasil.

${ }^{1}$ Enfermeira, Doutora em Enfermagem. Docente da Escola Superior de Ciências da Saúde. Brasília, DF, Brasil. E-mail: melomanuela91@gmail.com.

${ }^{2}$ Enfermeira, Doutora em Enfermagem. Professora Associado da Faculdade de Ciências da Saúde da Universidade de Brasília. Brasília, DF, Brasil. E-mail: E-mail: kamada@unb.br.

${ }^{3}$ Enfermeira, Mestre em Ciências da Saúde. Discente do Programa de PósGraduação em Ciências da Saúde da Universidade de Brasília. Brasília, DF, Brasil. E-mail: marinayyu95@gmail.com.

${ }^{4}$ Enfermeiro, Doutor em Ciências da Saúde. Professor Adjunto da Escola Superior de Saúde da Universidade de Aveiro. Aveiro, Portugal. E-mail: jflindo@ua.pt.

${ }^{5}$ Enfermeira, Doutora em Ciências e Tecnologias da Saúde. Professor Adjunto da Escola Superior de Saúde da Universidade de Aveiro. Aveiro, Portugal. E-mail: elsamelo@ua.pt.
}

Recebido: 04/09/2016

Aceito: 31/05/2017.

Publicado: 28/08/2017.

Como citar esse artigo:

Melo MC, Kamada I, Dutra LMA, Simões JFFL, Melo EMOP. Vivência do professor no cotidiano da criança com estomia: abordagem da Fenomenologia Social. Rev. Eletr. Enf. [Internet]. 2017 [acesso em:

____19:a33. Disponível em:

http://dx.doi.org/10.5216/ree.v19.43116.

\section{RESUMO}

Este estudo procurou compreender a vivência de professores no processo de inclusão de crianças com estomia, tendo como referencial a Fenomenologia Sociológica. Foram realizadas entrevistas, com cinco professores, no período entre dezembro de 2015 e janeiro de 2016. A coleta de dados foi efetuada por narração do professor, posterior transcrição e análise dos dados. Emergiram quatro categorias temáticas: sentimentos vividos pelos professores; fatores que interferem nos cuidados; estratégias eficazes para o cuidado; estratégias para melhoria dos cuidados. Os professores, valorizaram a integração da criança com estomia na escola; consideram que esta ocorre com a modificação da formação pedagógica; e apontaram a necessidade da presença do enfermeiro nas escolas. Os resultados mostram a importância do desenvolvimento de ações e estratégias de apoio aos professores e aos alunos com estomia no contexto de uma escola inclusiva, considerando que o enfermeiro escolar é determinante para a promoção em saúde destas crianças.

Descritores: Promoção da Saúde; Ensino Fundamental e Médio; Cuidados de Enfermagem; Pesquisa Qualitativa; Enfermagem Pediátrica.

\section{INTRODUÇÃO}

As famílias de crianças com problemas de saúde, particularmente, criança com estomia, passam por um período longo de tratamento e de adaptação, cujo impacto no crescimento e desenvolvimento infantil, envolve não apenas a dimensão biológica, 
mas também outras dimensões, influenciando as relações interpessoais, os relacionamentos grupais e intergrupais resultantes do convívio escolar e social; as atividades de lazer e a prática desportiva.

Muitas vezes estas crianças precisam ausentar-se da escola, e os problemas resultantes desta falta de participação requerem um trabalho em harmonia entre a própria criança, sua família, seus professores e os profissionais de saúde que acompanham o seu tratamento. Ao afastar-se da escola, algumas consequências negativas podem surgir na criança, tais como, déficit em suas habilidades cognitivas e motoras ${ }^{(1)}$.

Nesse sentido, os professores devem possibilitar aprendizagens que contribuam para que as crianças construam seu próprio conhecimento ao seu ritmo de desenvolvimento, tendo em consideração as restrições impostas pela situação da estomia, ou outra situação que necessite de cuidados especiais de saúde. Neste contexto, as estratégias de adaptação devem ser planejadas para a inclusão, conjuntamente com pais, criança, professores e profissionais de saúde. Todas as crianças têm o direito de estar em classes do ensino regular, desde que respeitada a individualidade pedagógica e terapêutica de cada uma, estimulando ao máximo o potencial de cada uma ${ }^{(2)}$. A inclusão deve envolver o aluno, a modificação do ambiente de aprendizagem, e a adequação do professor para o atendimento, favorecendo, assim, a promoção da saúde ${ }^{(1)}$.

A "promoção da saúde" é considerada, pela Organização Mundial da Saúde (OMS) ${ }^{(3)}$, fator essencial para a qualidade de vida. Este conceito amplamente divulgado a partir de 1986, com a Carta de Ottawa ${ }^{(4)}$, associa-se às estratégias de ações do Estado. Seguindo esta linha, no Brasil, em 2007, foi instituído o Programa Saúde na Escola (PSE) ${ }^{(5-6)}$, que apresenta diretrizes para a formação integral dos alunos, por meio de ações de promoção da saúde, prevenção de doenças e agravos à saúde, e atenção à saúde, inserindo o enfermeiro da Estratégia Saúde da Família no ambiente escolar, estratégia fortalecida também pela Política Nacional de Atenção Básica ${ }^{(7)}$.

O interesse em realizar um estudo que envolva o professor e a criança com estomia justifica-se na escassez de estudos da temática, como também, investir em pesquisas relacionadas à intervenção na estomaterapia. Nesse sentido, ao utilizar a abordagem fenomenológica sociológica de Alfred Schütz, procuramos, no aspecto intersubjetivo, os episódios narrados pelos professores e, assim, ampliamos a discussão do contexto da enfermagem no cuidado ao escolar.

A presente pesquisa objetivou compreender a vivência de professores no processo de inclusão de alunos com estomia na educação básica e especial.

\section{MÉTODO}

A investigação qualitativa constituiu o alicerce metodológico deste estudo e teve como referencial teórico-metodológico a Fenomenologia Social. O núcleo da fenomenologia social refere-se a sociologia das relações sociais e possui o sociólogo Alfred Schütz como um dos representantes da Fenomenologia Sociológica. Esse método fenomenológico está relacionado com compreensão das ações das pessoas na sua vida cotidiana, conscientes do mundo em que estão inseridas, apresentando, de maneira subjetiva, angústias, preocupações e relacionamentos interpessoais. Para a compreensão da realidade social, a 
Fenomenologia Sociológica valoriza a vivência no $\operatorname{cotidiano}^{(8)}$.

No início da investigação, fizemos contato com a enfermeira responsável pelo Grupo de Estomizados no hospital de referência no Distrito Federal, a qual forneceu o cadastro das crianças com estomia e, por meio dele, fizemos contato com cada familiar, informamos sobre os objetivos da pesquisa e soubemos que o filho frequentava a escola. Após identificação das crianças que frequentavam a escola, foi efetuado contato com a escola, através do seu diretor e posteriormente com o professor da criança.

Definimos como critério de inclusão para os participantes da pesquisa: professores que atendessem crianças com estomia em unidade escolar, da educação básica e especial, do Distrito Federal, e que as crianças estivessem cadastradas no grupo de estomizados do referido hospital. Como critério de exclusão: professores de unidades particulares de ensino. Foi considerado escolar toda a criança de zero a 10 anos, matriculadas em unidade educacional. $\mathrm{A} \mathrm{OMS}^{(3)}$ define criança como o período compreendido entre zero a 10 anos de idade.

$\mathrm{Na}$ construção das frases norteadoras, garantimos que estas incidissem sobre as experiências, as opiniões, as interações sociais e os sentimentos dos participantes. A coleta de dados foi realizada entre novembro de 2015 e janeiro de 2016.

Cada encontro fenomenológico foi realizado em local reservado, com a presença do entrevistado e da pesquisadora principal. Foi explicitado o objetivo da investigação, e esta teve início após autorização formal por meio da assinatura do Termo de Consentimento Livre e Esclarecido. Solicitamos autorização para o uso do gravador digital. Cada entrevista teve duração média de 30 a 40 minutos.

No decorrer das entrevistas, após a quarta, constatamos que houve pouca variância nas narrativas, resultando na saturação dos dados, pelo que completamos a colheita de dados com cinco entrevistas.

Depois da realização da pesquisa de campo, cada narração foi transcrita e em seguida, efetivada a leitura, procurando a familiarização com o texto e as experiências dos participantes. Para a garantia do anonimato, os depoimentos foram identificados pela letra " $\mathrm{P}$ " (Professor), por ordem cronológica das entrevistas, tendo sido identificados de P1 a P5.

Cada narração foi cuidadosamente lida e relida por várias vezes, buscando encontrar significados e posteriormente a síntese. Este processo foi realizado com o objetivo de examinar minuciosamente o que foi narrado e, assim, elucidar o contexto no todo, apresentando as experiências do fenômeno vivido pelos participantes.

Foram garantidos os procedimentos nacionais e internacionais de ética em pesquisa envolvendo seres humanos, tendo o estudo sido aprovado pelo Comitê de Ética em Pesquisa da Fundação de Ensino e Pesquisa em Ciências da Saúde, sob o parecer no 1.257.739 de 2015. 


\section{RESULTADOS}

\section{Caracterização dos participantes}

Relativamente a caracterização dos cinco professores entrevistados, verificamos que a maioria são do sexo feminino, idade entre 20 e 40 anos, religião católica, moradores do Distrito Federal, em regionais administrativas próximas ao local de trabalho. Com relação ao emprego, todos trabalham na Secretaria de Educação do Distrito Federal. Verificamos ainda que todos os entrevistados tinham um curso de pósgraduação. Quanto à capacitação para o atendimento do aluno com estomia, todos afirmaram que não receberam qualquer formação na área.

A idade dos alunos atendidos variava entre cinco e nove anos, em relação ao tipo de estomia, três crianças tinham uma estomia intestinal e dois uma estomia gástrica - estes dois com graves comprometimentos neurológicos.

Todos os participantes confirmaram que os seus alunos eram dependentes dos cuidados com a estomia e possuíam os monitores, que eram seus apoiadores no cuidado e na inclusão destes alunos.

\section{Análise qualitativa}

Ao se realizar uma análise mais abrangente das narrações, os professores foram unânimes em narrar que na inserção do aluno com estomia, ou com necessidades especiais de saúde, ocorria a necessidade de modificação na formação da própria prática pedagógica para atender, com qualidade, a individualidade de cada estudante. Outro aspecto referido foi a presença do profissional de saúde, que facilitaria o cuidado e a atenção prestados ao aluno com estomia no ambiente escolar.

A leitura atenta e crítica das narrações dos participantes oportunizou compreender o fenômeno sendo assim reconhecidas quatro categorias temáticas e seus aspectos relevantes.

\section{Sentimentos vividos pelos professores em ambiente escolar}

Definiu-se, neste estudo, por sentimento, a ação ou efeito de sentir e a disposição para ser facilmente comovido ou impressionado. Foram identificadas duas subcategorias: sentimentos positivos e negativos.

Para os professores, os sentimentos positivos foram expressos pelos indicadores sensibilidade, desafio, interesse, alegria e recompensa.

Eu converso muito com os pais, e eles falam muito da insatisfação, pois vivem em função do filho (...) e precisam permanecer na escola enquanto o filho estuda (P2).

(...) trabalhar com esse tipo de criança tem de gostar do que faz, porque muitas vezes o que vai permanecer no atendimento com esse aluno é você gostar da sua profissão (P3).

Com relação aos sentimentos negativos, foram encontrados os indicadores frustração, incapacidade e insegurança. 
(...) os servidores da educação [os professores] não receberam qualquer curso ou instrução da secretaria de educação e/ou saúde para tais cuidados, sejam cuidados simples ou não (...) com a estomia, medicações $e$ curativos simples (...) (P2).

\section{Fatores que interferem nos cuidados}

Partindo do pressuposto de que a escola era um eixo estratégico para a promoção da saúde, esta categoria envolveu os fatores que interferiram nessa estratégia para a inclusão do aluno com estomia. Definimos como fatores qualquer elemento que contribuísse para a obtenção de um resultado, como exemplo, recursos humanos, materiais e a situação clínica do aluno. $\mathrm{Na}$ análise das narrações, foram identificadas as seguintes subcategorias, os recursos utilizados e a dimensão da criança.

Na subcategoria recursos utilizados, foram identificadas três indicadores: recursos humanos, recursos materiais disponíveis e não disponíveis.

Nós tentamos fazer o máximo, na escola não tem espaço para cuidar da criança, o que temos é um espaço improvisado, fica no banheiro do ensino especial (...) (P1).

Um problema que vivencio é a falta do preparo pra atender essas crianças (P3).

$\mathrm{Na}$ segunda subcategoria, dimensão da criança, buscamos identificar os fatores envolvidos diretamente com a criança, fossem a cognição, sua limitação física ou intelectual, a distância do local de sua moradia à escola, ou a sua estrutura familiar.

(...) a criança nessa situação também precisa de atenção, e quando a criança tem adaptações, requer todo um cuidado, como exemplo, na aplicação de tarefas, preciso pensar na estomia (...) (P3).

\section{Estratégias eficazes para o cuidado}

Esta categoria temática buscou no termo "estratégia" informar como os professores conseguiam ultrapassar o problema da inclusão escolar. Encontraram-se duas subcategorias relevantes: a estratégia usada no primeiro contato e no dia a dia.

Na subcategoria estratégia usada no primeiro contato, foi apresentada como válida a conversa com a mãe ou familiares, identificando a situação clínica, física e intelectual do aluno.

Quando a gente vai receber criança com algum problema, nós pedimos um relatório médico, informando, o que aconteceu, porque da colostomia. (...) um resumo (P4).

Na subcategoria estratégias utilizadas no dia a dia foram identificados os seguintes indicadores: perseverança, individualidade e ter o material para o atendimento.

(...) terão dias em que haverá atividades propostas, mas que só serão realizadas caso ele esteja bem, dependendo de como ele estiver (...) não conseguirá realizar (P3). 


\section{Estratégias para melhoria dos cuidados}

Nesta última categoria, as narrações apresentaram as possibilidades de melhoria para o cuidado. Nas estratégias foram identificadas quatro subcategorias: construção do material educativo de orientação nos cuidados ao aluno com estomia; atendimento multiprofissional, como o apoio do profissional de saúde; adequação ao ambiente; e a capacitação para o atendimento.

Seria muito interessante algo que ajudasse os professores no cuidado a criança com estoma, por exemplo, uma cartilha que auxilie os profissionais, pais/ responsáveis (...) (P2).

Fica um desabafo, em teoria um CEE [Centro de Educação Especial] deve ter um profissional de saúde responsável no cuidado direto com essas crianças (...), um enfermeiro além dos profissionais já existentes: pedagogo $e$ educador físico (P3).

\section{DISCUSSÃO}

A proposta do estudo foi aprofundar o conhecimento sobre esta temática a partir das narrações dos sujeitos; buscamos, estabelecer, os princípios legais que orientam os Estados signatários a adotarem medidas em favor da educação inclusiva ${ }^{(9-10)}$.

No Brasil, os princípios da inclusão possuem apoio da Lei de Diretrizes e Bases da Educação Nacional. Em 2008, foi lançada a Política Nacional de Educação Especial na Perspectiva da Educação Inclusiva, que tratou da exclusão e desvalorização atribuída aos alunos, fundamentadas na concepção dos Direitos Humanos e da sua diversidade ${ }^{(11)}$.

Neste estudo, os professores narraram que a inserção do aluno com estomia faz com que ocorra modificação da formação da própria prática pedagógica para atender a diversidade. Sendo assim, há respaldo na lei, pois, o indivíduo com estomia possui deficiência, de acordo com o decreto 5.296, de 2 de dezembro de 2004, o qual "considera-se a estomia uma deficiência física, garantindo direitos às pessoas com estomias"(12). No apoio a formação, em 2004, foi encaminhada a Carta de Brasília ao Ministério de Educação, a qual solicita a inclusão do tema estomia nos treinamentos de professores ${ }^{(13)}$. Em 2011, o decreto 7.611 garantiu o atendimento do estomizado como público da educação especial ${ }^{(14)}$.

Atender na adversidade faz com que o professor apresente, além da qualidade de educador, a de facilitador, no intuito de promover um ambiente propício à educação. Trabalhar na adversidade sugere um desafio, segundo o qual o professor precisa transpor as suas próprias limitações para poder encontrar os seus novos saberes e fazeres ${ }^{(15)}$. É neste sentido, que a fenomenologia social apresenta ao professor a compreesão dos desafios da educação inclusiva.

Um estudo desenvolvido com professores de escola inclusiva apresenta a inclusão como sugestão para amenizar os sentimentos angustiantes e propõe que "além da formação continuada é fundamental que o professor conte com uma rede de apoio na escola para auxiliá-lo no desenvolvimento de seu trabalho"(15). Além dos problemas inerentes à educação inclusiva, os professores se deparam com a estomia, situação que intensifica os sentimentos apresentados. Desse modo, o problema é identificar quem é a pessoa responsável por esse atendimento ${ }^{(15-17)}$. A presença do enfermeiro na escola ajudaria o atendimento com qualidade, 
por ser um profissional habilitado no cuidado integral ao individuo.

A atuação do enfermeiro escolar, no Brasil, data da década de 1930, seguindo o modelo americano, com o objetivo de atender a demanda profissional no setor da educação na melhoria das condições de saúde dos escolares ${ }^{(18)}$. Um dos motivos para esta demanda foi a ausência do profissional médico nas regiões longínquas do país, o qual objetivou formar o educador sanitário. Este era inicialmente direcionado para as normalistas - antigo curso que formava professores para o ensino, hoje conhecido como fundamental -, e posteriormente estendeu-se a portadores de diplomas de curso superior, entre eles o enfermeiro ${ }^{(19)}$.

No Brasil, não há obrigatoriedade do enfermeiro nas escolas, mas há a atuação do enfermeiro do Programa de Saúde da Família no ambiente escolar, promovendo ações de prevenção e promoção aos escolares e profissionais da educação. Como exemplo, referimos um estudo desenvolvido no município do Rio de Janeiro, o qual descreveu o perfil e as práticas dos enfermeiros da Equipe de Saúde na Família voltadas para a saúde de escolares. Este Programa de Saúde nas Escolas (PSE), mostrou que a permanência desse profissional está relacionada ao seu envolvimento com os serviços prestados e sua identificação com estes modelos $^{(20)}$, além de maior incentivo governamental a essa prática.

Os resultados encontrados neste estudo, são também idênticos a um estudo desenvolvido em Tomar, Portugal, no qual a parceria pedagógica dentro da sala de aula foi verificada como estratégia de mudança para desenvolver melhores condições de gerir a diversidade na aprendizagem ${ }^{(21)}$, ou seja, o papel ativo entre os professores é um elemento primordial para a eficácia do processo de inclusão, e a sua ação pedagógica configura as suas experiências adquiridas em contextos educacionais.

Os professores narraram ainda, a relevância de contar com a equipe multiprofissional colaboradora de um ensino de qualidade. Estas referências são idênticas às de um estudo realizado com professores da cidade de São Paulo que atendiam crianças com deficiência, reforçando essa relevância. Neste sentido referem que além de diferentes profissionais do campo da educação, é necessário também o profissional na área da saúde na rede de apoio para inclusão de crianças com deficiência ${ }^{(17)}$.

A presença do enfermeiro na escola envolve o planejamento da assistência direta ao escolar e o apoio aos educadores, facilitando a inclusão do aluno com deficiência, pois contribui para a sua assistência integral desde o início do quadro clínico, perpassando a implantação do dispositivo tecnológico, a estomia, e atuando nas intervenções e reabilitação.

\section{CONCLUSÃO}

Este estudo explorou a compreensão de professores no processo de inclusão de alunos com estomia na educação básica. Essa compreensão teve como ponto de partida a experiência vivida, acessada por meio de entrevistas fenomenológicas.

As evidências desta investigação reforçam os entraves para a inclusão do aluno com estomia, narradas pelos professores, e apresentaram a necessidade de o currículo dos cursos de formação permanente e especialização serem revistos e que as estratégias utilizadas pelos professores sejam ampliadas, no intuito 
de adequá-las à temática da estomia, e assim, favorecer a promoção da saúde desses alunos. Além disso, evidenciou a necessidade da presença do enfermeiro nas unidades escolares de ensino, não apenas no atendimento do aluno deficiente, mas nos cuidados curativos e preventivos em saúde, tais como nos acidentes escolares, no controle de doenças infecto contagiosas, nas ações da educação em saúde, entre outros.

Identificamos como limitação deste estudo a participação de um grupo específico de atendimento na unidade escolar, o que impossibilita a generalização dos resultados. No entanto, as evidências científicas devem ser valorizadas e utilizadas, e podem contribuir para a qualidade do atendimento ao aluno com estomia.

Este estudo exibe relevância pela necessidade de investimentos em pesquisas relacionadas à intervenção no atendimento do aluno com estomia, com a finalidade de instrumentalizar o cuidado e ampliar o corpo de conhecimento teórico fundamentado em evidências científicas.

\section{Financiamento}

Este estudo recebeu o apoio financeiro do Colégio Doutoral Tordesillas Enfermagem (CDTE).

\section{REFERÊNCIAS}

1. Maher AJ. Special educational needs in mainstream secondary school physical education: learning support assistants have their say. Sport Educ Soc [Internet]. 2016 [acesso em: 28 ago. 2017];21(2):262-78. Disponível em: http://dx.doi.org/10.1080/13573322.2014.905464.

2. Ministério da Educação. Direito à educação: subsídios para a gestão dos sistemas educacionais [Internet]. 2a ed. Brasília: MEC/SEESP; 2016 [acesso em: 28 ago. 2017]. Disponível em: http://portal.mec.gov.br/seesp/arquivos/pdf/direitoaeducacao.pdf.

3. World Health Organization. Physical status: the use of and interpretation of anthropometry. Report of a WHO Expert Committee. Geneva: World Health Organization; 1995 [acesso em: 28 ago. 2017]. Disponível em: http://apps.who.int/iris/bitstream/10665/37003/1/WHO_TRS_854.pdf.

4. Ministério da Saúde, Secretaria de Políticas de Saúde, Projeto Promoção da Saúde. As cartas da promoção da Saúde. Brasília: Ministério da Saúde; 2002 [acesso em: 28 ago. 2017]. Disponível em:

http://bvsms.saude.gov.br/bvs/publicacoes/cartas_promocao.pdf.

5. Ministério da Saúde; Ministério da Educação. Programa Saúde na Escola. Manual Instrutivo 2013 [Internet]. Brasília: Ministério da Saúde; 2013 [acesso em: 28 ago. 2017]. Disponível em:

http://www.pmf.sc.gov.br/arquivos/arquivos/pdf/19_06_2013_16.21.18.880166244cb983df2c85e0bcc746a73b.pdf. 6. Rasche AS, Santos MSS. Enfermagem escolar e sua especialização: uma nova ou antiga atividade. Rev Bras Enferm [Internet]. 2013 [acesso em: 28 ago. 2017];66(4):607-10. Disponível em: http://dx.doi.org/10.1590/S003471672013000400022.

7. Portaria no 2.488, de 21 de outubro de 2011 (BR) [Internet]. Aprova a Política Nacional de Atenção Básica, estabelecendo a revisão de diretrizes e normas para a organização da Atenção Básica, para a Estratégia Saúde da Família (ESF) e o Programa de Agentes Comunitários de Saúde (PACS). Diário Oficial da União. 24 out. 2011 [acesso em: 28 ago. 2017]. Disponível em: http://bvsms.saude.gov.br/bvs/saudelegis/gm/2011/prt2488_21_10_2011.html. 8. Schutz A. Sobre fenomenologia e relações sociais. Rio de Janeiro: Vozes; 2012. 360 p.

9. Greguol M, Gobbi E, Carraro A. Formação de professores para a educação especial: uma discussão sobre os modelos brasileiro e italiano. Rev. bras. educ. espec. [Internet]. 2013 [acesso em: 28 ago. 2017];19(3):307-24. Disponível em: http://dx.doi.org/10.1590/S1413-65382013000300002. 
10. Rahme MMF. Inclusão e internacionalização dos direitos à educação: as experiências brasileira, norte-americana e italiana. Educ. Pesqui. [Internet]. 2013 [acesso em: 28 ago. 2017];39(1):95-110. Disponível em:

http://dx.doi.org/10.1590/S1517-97022013000100007.

11. Ministério da Saúde, Secretaria de Atenção à Saúde, Departamento de Ações Programáticas Estratégicas. Política Nacional de Saúde da Pessoa com Deficiência [Internet]. Brasília: Ministério da Saúde; 2010 [acesso em: 28 ago. 2017$].$ Disponível em: http://bvsms.saude.gov.br/bvs/publicacoes/politica_nacional_pessoa_com_deficiencia.pdf.

12. Ministério da Saúde, Secretaria de Atenção à Saúde, Departamento de Ações Programáticas Estratégicas. Manual de legislação em saúde da pessoa com deficiência [Internet]. 2ª ed. Brasília: Ministério da Saúde; 2006 [acesso em: 28 ago. 2017]. Disponível em: http://bvsms.saude.gov.br/bvs/publicacoes/legislacao deficiencia.pdf.

13. Associação Brasileira de Ostomizados. Carta de Brasília [Internet]. Brasília, 2004 [acesso em: 28 ago. 2017]. Disponível em: http://www.sobest.org.br/arquivos/Carta_Brasilia.pdf.

14. Decreto no 7.611, de 17 de novembro de 2011 (BR) [Internet]. Dispõe sobre a educação especial, o atendimento educacional especializado e dá outras providências. Diário Oficial da União. 18 nov. 2011 [acesso em: 28 ago. 2017 ]. Disponível em: http://www.planalto.gov.br/ccivil_03/_ato2011-2014/2011/decreto/d7611.htm.

15. Briant MEP, Oliver FC. Inclusão de crianças com deficiência na escola regular numa região do município de São Paulo: conhecendo estratégias e ações. Rev. bras. educ. espec. [Internet]. 2012 [acesso em: 28 ago. 2017];18(1):14154. Disponível em: http://dx.doi.org/10.1590/S1413-65382012000100010.

16. Menezes HF, Góes FGB, Souza ALS, Maia SMA. A autonomia da criança estomizada: desafios para o cuidado de enfermagem. Rev enferm UFPE on line. [Internet]. 2014 [acesso em: 28 ago. 2017];8(3):632-40. Disponível em: http://www.revista.ufpe.br/revistaenfermagem/index.php/revista/article/view/5104.

17. Bragheto ACM, Carvalho AMP. Desempenho escolar, comportamental e desenvolvimento cognitivo e emocional de crianças infectadas pelo HIV: estudo preliminar. Revista Enfermagem UERJ [Internet]. 2013 [acesso em: 28 ago. 2017];21(1):29-33. Disponível em: http://www.e-publicacoes.uerj.br/index.php/enfermagemuerj/article/view/6343. 18. Marcondes RS. Educação em saúde na escola. Rev Saude Publica [Internet]. 1972 [acesso em: 28 ago. 2017];6(1):89-96. Disponível em: http://dx.doi.org/10.1590/S0034-89101972000100010. 19. Ferriani MGC, Gomes R. Saúde escolar: contradições e desafios. Goiânia: AB Editora; 1997.

20. Fontenele RM, Sousa AI, Rasche AS. Saúde ocular em escolares e a prática dos enfermeiros da atenção básica. Cogitare Enferm [Internet]. 2016 [acesso em: 28 ago. 2017];21(1). Disponível em: http://dx.doi.org/10.5380/ce.v21i4.41889.

21. Tavares C, Sanches I. Gerir a diversidade: contributos da aprendizagem cooperativa para a construção de salas de aula inclusivas. Revista Portuguesa de Educação [Internet]. 2013 [acesso em: 28 ago. 2017];26(1):307-47. Disponível em: http://revistas.rcaap.pt/rpe/article/view/2994. 